\title{
Quantification of arsenic adsorption and oxidation on manganese oxides
}

\author{
B. Rathi ${ }^{1}$, O. Cirpka ${ }^{1}$, J. Sun ${ }^{2}$, J. Jamieson ${ }^{2}$, A. Siade ${ }^{2}$, H. Prommer ${ }^{2} \&$ M. Zhu ${ }^{3}$ \\ ${ }^{1}$ Centre for Applied Geoscience, University Tübingen, Tübingen, Germany \\ ${ }^{2}$ University of Western Australia and CSIRO Land and Water, Perth, Australia \\ ${ }^{3}$ Department of Ecosystem Science and Management, University of Wyoming, Laramie, WY, USA
}

\begin{abstract}
Oxidation of arsenite (As(III)) by manganese (Mn) oxide minerals commonly found as coatings on aquifer sediments can be an important process controlling arsenic mobility in many aquifers. To date the mechanistic details of As(III) oxidation process have only been described qualitatively in a number of studies, however, these mechanisms vary markedly with respect to the intermediate reactions involved and the products formed. We carried out a detailed geochemical analysis of key literature datasets by translating the known reaction mechanisms into conceptual models of sequentially increasing complexities. These conceptual models were then tested for their feasibility in a numerical modelling framework. The results of this modelling exposed significant limitations in the current conceptual models. Although none of the model simulations produced accurate fit to the data, we were able to ascertain that As(III) oxidation by Mn oxides is most likely a two-step process in which the rate of first oxidation step was dependent only on a small fraction of the Mn oxide initially present in the system. The second rate of oxidation step was slower than first and was responsible for producing Mn(II) ions. The conceptual models can be further improved with data on solid phase characterisation of Mn mineralogy and speciation of adsorbed species during the experiments. This modelling framework provides a good foundation for assessing the influence of other geochemical factors on As(III) oxidation in future research.
\end{abstract}

\section{INTRODUCTION}

Arsenite, As(III), mobility and toxicity can be dramatically reduced due to oxidation by $\mathrm{Mn}$ oxides that are ubiquitous in soils and sediments (Post, 1999). Despite a large set of studies investigating As(III) oxidation by both laboratory synthesized and natural Mn oxides, the details of the proposed reaction mechanisms vary markedly with respect to the intermediate steps involved, the contribution of surface reactions, and the surface properties of Mn oxides (e.g., Oscarson et al., 1983; Scott \& Morgan, 1995; Nesbitt et al., 1998). Furthermore, the extent of As(III) oxidation can be affected by a wide range of geochemical factors, including the solution $\mathrm{pH}$, competing solutes (Fe(II), phosphate, etc.) and specific Mn mineralogy. So far, only a few attempts have been made to quantify As(III) oxidation by Mn oxides (e.g., Amirbahman et al., 2006; Rathi et al., 2017) and they do not follow a rigorous process-based modelling approach to interrogate the intermediate surface reactions and the prevailing geochemical conditions that influence the extent and rate of As(III) oxidation. This study aims to review the known As(III) oxidation mechanisms and to develop and evaluate suitable process-based modelling approaches against the experimental data available in the literature.

\section{METHODS}

\subsection{Dataset and modelling approach}

Datasets from both batch (Manning et al., 2002) and flow (Lafferty et al., 2010) experiments were used to test the conceptual models. Batch experiments were conducted at $\mathrm{pH} 6.50$ with acid-Birnessite. Flow experiments were conducted at $\mathrm{pH} 7.20$ with deltaBirnessite. Both types of Birnessites differ in their crystal size and hence the surface area. Both experiments provided data on aq. As(III) and arsenate, $\mathrm{As}(\mathrm{V})$, concentrations in additional to aqueous $\mathrm{Mn}(\mathrm{II})$ concentrations from flow experiments. The geochemical modelling code PHREEQC (Parkhurst \& Appelo, 1999) and reactive transport modelling code PHT3D (Prommer et al., 2003) were used to analyze experiment data. The adsorption reactions of $\mathrm{As}(\mathrm{III}), \mathrm{As}(\mathrm{V})$ and $\mathrm{Mn}(\mathrm{II})$ were modelled using surface complexation approach and redox transformations between As(III) and $\mathrm{As}(\mathrm{V})$ were assumed to be kinetically controlled.

\subsection{Conceptual models}

The current understanding of the oxidation process was evaluated by translating three specific sets of 


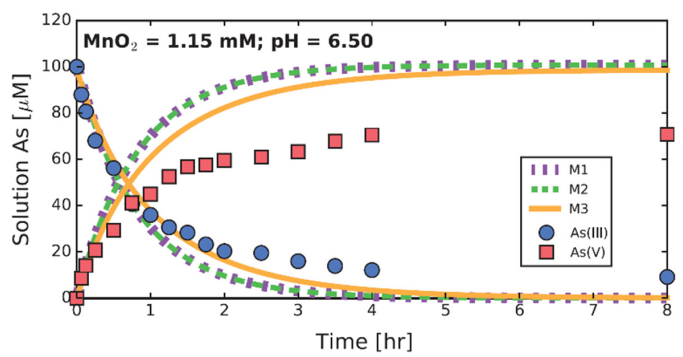

Figure 1. Simulation results of models M1 to M3 for data from laboratory batch experiments (Manning et al., 2002).

processes into separate model variants and by investigating the replicability of the model output to the available data. The simplest model variant, in which oxidation was considered to occur as a one-step process, followed the reaction

$\mathrm{MnO}_{2}+\mathrm{H}_{3} \mathrm{AsO}_{3}+\mathrm{H}^{+} \rightarrow \mathrm{Mn}^{2+}+\mathrm{H}_{2} \mathrm{AsO}_{4}^{-}+\mathrm{H}_{2} \mathrm{O}$

and was defined as the base model (M1). Subsequently, one or more degrees of complexity were sequentially added to consider kinetically controlled oxidation in two steps by mineral $\mathrm{MnO}_{2}$ (s) and an intermediate product $\mathrm{MnOOH}^{*}$ (s), either without (model M2) or with adsorption of aqueous species (model M3).

\section{RESULTS AND DISCUSSION}

\subsection{Results of models M1 and M2}

Model M1 results failed to capture the observed temporal concentration changes of all aqueous species in both batch and flow experiments (Figs. 1 and 2). The simulations of both experiments matched observed $\mathrm{As}(\mathrm{III})$ and $\mathrm{As}(\mathrm{V})$ concentrations initially followed by being underestimated for As (III) and overestimated for $\mathrm{As}(\mathrm{V})$ in the remaining duration. Aq. $\mathrm{Mn}(\mathrm{II})$ was overestimated while following an $\mathrm{As}(\mathrm{V}): \mathrm{Mn}(\mathrm{II})$ ratio of 1:1 throughout M1 simulation. These results suggest that the one-step oxidation model lacked key processes, which would slow As(III) adsorption over time and cause retention of a fraction of $\mathrm{As}(\mathrm{V})$ and $\mathrm{Mn}(\mathrm{II})$ on $\mathrm{Mn}$ oxides.

\subsection{Numerical implementation of model M2}

Model M2 incorporates two-step As(III) oxidation reactions with $\mathrm{MnO}_{2}$ (s) and $\mathrm{MnOOH}^{*}$ (s) (Nesbitt et al., 1998):

$2 \mathrm{Mn}^{\mathrm{IV}} \mathrm{O}_{2}(\mathrm{~s})+\mathrm{H}_{3} \mathrm{AsO}_{3}+\mathrm{H}_{2} \mathrm{O} \rightarrow$

$2 \mathrm{Mn}^{\mathrm{III}} \mathrm{OOH}^{*}(\mathrm{~s})+\mathrm{H}_{3} \mathrm{AsO}_{4}+2 \mathrm{H}^{+}$

and

$2 \mathrm{Mn}^{\mathrm{III}} \mathrm{OOH}^{*}(\mathrm{~s})+\mathrm{H}_{3} \mathrm{AsO}_{3}+4 \mathrm{H}^{+} \rightarrow 2 \mathrm{Mn}^{2+}+$

$\mathrm{H}_{3} \mathrm{AsO}_{4}+3 \mathrm{H}_{2} \mathrm{O}$
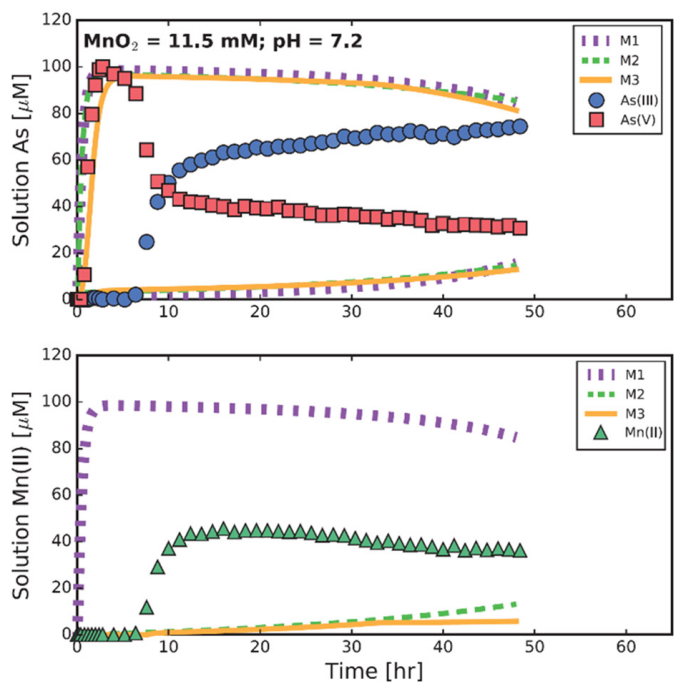

Figure 2. Simulation results of models M1 to M3 for data from laboratory flow experiment (Lafferty et al., 2010).

M2 simulations produced identical results to M1 except for $\mathrm{Mn}$ (II) concentrations in the flow experiment where the delayed appearance of $\mathrm{Mn}$ (II) was captured better than M1 (Figs. 1 and 2). M2 results show that oxidation was predominantly caused by $\mathrm{MnO}_{2}(\mathrm{~s})$ suggesting that only a fraction of the total $\mathrm{MnO}_{2}$ (s) was required for As(III) oxidation at the onset of every experiment.

\subsection{Numerical implementation of model M3}

Model M3 was also setup by modifying model M2 to include adsorption reactions of $\mathrm{As}(\mathrm{III})$ and $\mathrm{As}(\mathrm{V})$, and the oxidation rates dependent only on the concentrations of adsorbed $\mathrm{As}(\mathrm{III}) . \mathrm{MnO}_{2}$ (s) and $\mathrm{MnOOH}^{*}(\mathrm{~s})$ were both assumed to provide surface sites $>\mathrm{Mn}^{\mathrm{IV}}$ and $>\mathrm{Mn}^{\mathrm{III}}$, respectively:

$2\left(>\mathrm{Mn}^{\mathrm{IV}}-\mathrm{OH}\right)+\mathrm{H}_{3} \mathrm{As}^{\mathrm{III}} \mathrm{O}_{3}+\mathrm{H}_{2} \mathrm{O} \rightarrow$

$2\left(>\mathrm{Mn}^{\mathrm{III}}-\mathrm{OH}\right)+\mathrm{HAs}^{\mathrm{V}} \mathrm{O}_{4}^{2-}+2 \mathrm{H}^{+}$

and

and $2\left(>\mathrm{Mn}^{\mathrm{III}}-\mathrm{OH}\right)+\mathrm{H}_{3} \mathrm{As}^{\mathrm{III}} \mathrm{O}_{3} \rightarrow 2 \mathrm{Mn}^{2+}+$ $\mathrm{HAs}^{\mathrm{V}} \mathrm{O}_{4}^{2-}+\mathrm{H}_{2} \mathrm{O}+4 \mathrm{H}^{+}$

The results of the M3 yielded a slightly improved calibration of the aq. As(III) and $\mathrm{As}(\mathrm{V})$ concentrations observed in the batch experiment, but failed to reproduce the results of the flow experiment (Figs. 1 and 2). Oxidation was predominantly caused by $\mathrm{MnO}_{2}$ (s) and surface passivation was minor.

\section{CONCLUSIONS}

The numerical implementation of all conceptual models (M1 to M3) showed some major limitations in the 
reactions mechanisms proposed in the literature. None of the models could simulate the observed arsenic or $\mathrm{Mn}(\mathrm{II})$ data and point towards the possibility that only a limited fraction of the Mn oxides effectively participates in the reactions. A detailed information on the solid phase characterisation of Mn mineralogy and speciation of adsorbed species could provide more data to improve our understanding of As(III) oxidation mechanism.

The numerical model that simulates As(III) oxidation by $\mathrm{Mn}$ oxides is relevant for a wide range of scenarios in natural groundwater systems. High abundance of Mn oxide coatings on natural sediments inadvertently impose significant influence on arsenic mobility in groundwater. This study has explored interaction between arsenic and pure Mn oxides and provides a good foundation for assessing the influence of other solution species or chemical factors in future research. Development of a modelling framework based on adsorption and surface oxidation mechanisms supports a more refined understanding of the complex interaction between arsenic and Mn oxides.

\section{ACKNOWLEDGEMENTS}

We acknowledge the financial support provided by UWA and CSIRO through postgraduate scholarship and travel funding.

\section{REFERENCES}

Amirbahman, A., Kent, D.B., Curtis, G.P. \& Davis, J.A. 2006. Kinetics of sorption and abiotic oxidation of arsenic(III) by aquifer materials. Geochim. Cosmochim. Acta 70: 533-547.
Lafferty, B.J., Ginder-Vogel, M. \& Sparks, D.L. 2010. Arsenite oxidation by a poorly crystalline manganese-oxide 1. stirred-flow experiments. Environ. Sci. Technol. 44: 8460-8466.

Manning, B.A., Fendorf, S.E., Bostick, B. \& Suarez, D.L. 2002. Arsenic(III) oxidation and Arsenic(V) adsorption reactions on synthetic birnessite. Environ. Sci. Technol. 36: 976-981.

Nesbitt, H.W., Canning, G.W. \& Bancroft, G.M. 1998. XPS study of reductive dissolution of $7 \AA \AA$-birnessite by $\mathrm{H} 3 \mathrm{AsO} 3$, with constraints on reaction mechanism. Geochim. Cosmo-chim. Acta 62: 2097-2110.

Oscarson, D.W., Huang, P.M., Liaw, W.K. \& Hammer, U.T. 1983. Kinetics of oxidation of arsenite by various manganese dioxides. Soil Sci. Soc. Am. J. 47: 644-648.

Parkhurst, D.L. \& Appelo, C.A.J. 1999. User's guide to PHREEQC (version 2) a computer program for speciation, batch-reaction, one-dimensional transport, and inverse geo-chemical calculations. Open-File Reports Vol. XIV, U.S. Geological Survey: Earth Science Information Center.

Post, J.E. 1999. Manganese oxide minerals: Crystal structures and economic and environmental significance. Proc. Natl. Acad. Sci. U.S.A. 96: 3447-3454.

Prommer, H., Barry, D.A. \& Zheng, C. 2003. MOD-FLOW/ MT3DMS-based reactive multicomponent transport modeling. Ground Water. 41: 247-257.

Rathi, B., Neidhardt, H., Berg, M., Siade, A. \& Prommer, H. 2017. Processes governing arsenic retardation on Pleistocene sediments: Adsorption experiments and model-based analysis. Water Resour. Res. 53: 4344-4360.

Scott, M.J. \& Morgan, J.J. 1995. Reactions at Oxide Surfaces. 1. Oxidation of As(III) by Synthetic Birnessite. Environ. Sci. Technol. 29: 1898-1905. 